\title{
Introduction to Advances Historical Studies-Newton Special Issue. History and Historical Epistemology of Science
}

In Philosophiae Naturalis Principia Mathematica Newton wrote: "Since the ancients (according to Pappas) considered mechanics to be of the greatest importance in the investigation of nature and science and since the modern-rejecting substantial forms and occult qualities-have undertaken to reduce the phenomena of nature to mathematical laws, it has seemed best in this treatise to concentrate on mathematics as it relates to natural philosophy." (Preface, The Cambridge Trinity College, May 8, 1686).

Newton offered a new approach to science establishing a standard in the treatment of mechanics. The latter is divided in a pure part, essentially mathematical in nature, and an applicative part, where mathematics becomes the tool for account for physical (mainly celestial) phenomena. In studying Newton's science, one may then focus on mathematics and study the way it allow one to treat with physical phenomena. Therefore, starting from Newton and his rational mechanics, a new fundamental research-field emerges: mathematical-physics, dealing with the relation between mathematical and physical quantities: i.e., how time as occurring in geometrical arguments is related to time understood as a physical magnitude? The answer to these questions is relevant for three disciplines: 1) history of science (physics and mathematic s); 2) epistemology; 3) physics itself.

The evolution of Newton's setting resulted from the middle of $18^{\text {th }}$ and during the $19^{\text {th }}$ centuries in new scientific approaches also involving interplay between pure mathematical developments (differential and integral calculus) and the study of physical phenomena (of different sorts). Thus, a new relation between mathematical structure and physical quantities emerges. Relationship physics and mathematics both in the Newtonian and the posterior settings: physical and mathematical objects, and heritage of Newtonian's science, concerning Newtonian foundations in others sciences in the history.

This Special Issue deals with important issues linking science, historical, epistemological and foundational aspects of science. It is meaningful for the Advances in Historical Studies to which this special issue is addressed. I will like to congratulate with each and everyone for the efforts in aggregating so distinguished topics, and obtaining a valuable result of a comprehensive survey of historical achievements in the bridging science, history and historical epistemology of science.

Clearly, the authors explain the various ways in which the sciences allowed advanced historical hypotheses on the one hand, and the development of new standpoints on the other hand. The scholars from different traditions discuss on the emergency style thinking in methodology and in theoretical perspective aiming to gather and re-evaluate the current thinking on this subject. It brings together contributions from leading experts in the field, and gives much-needed insight in the subject from a historical point of view, as well; taken as a whole, the volume is testament to a broad, and thriving, interdisciplinarity in subject area, as well as an absence of historiographical dogma.

This special issue volume composition makes for absorbing reading for historians, epistemologists, philosophers and scientists.

Enjoy the stimulating reading!

Raffaele Pisano, Editor in Chief 